\title{
JUVENTUDE E PROJETOS DE FUTURO EM RELATOS DE ESTUDANTES DE ENSINO MÉDIO DE ESCOLAS PÚBLICAS
}

\author{
Raquel Souza Coelho' \\ Thelma Maria Grisi Velôso
}

\section{Introdução}

Em extensa pesquisa bibliográfica acerca do tema, Zanella et al (2013: 329) não identificaram, em grande parte da produção científica, uma definição clara do que é juventude. Além disso, enquanto alguns a consideram "dentro de uma faixa etária variada", outros a concebem como sinônimo de adolescência, e restringem-na a "uma fase da vida". Segundo os referidos autores, existem múltiplas definições de juventude na sociedade, e isso se expressa na produção científica. Há, no entanto, um predomínio, na produção teórica, da concepção de juventude construída a partir da ideia de uma vida vivida em fases. Nessa visão, a juventude seria apenas uma fase de transição, um vácuo existencial sem possibilidades, limites, direitos ou deveres.

Na bibliografia socioantropológica, segundo Gonçalves e Knauth (2006), a juventude tem sido definida como um valor simbólico, identificado com um estilo de consumo no Ocidente na atualidade. Conforme Debert (2006), a pesquisa antropológica evidencia que a idade não define naturalmente grupos sociais, não explica comportamentos nem é um dado da natureza. Os períodos da vida são processos biológicos elaborados simbolicamente, e cujas fronteiras são diferentes em cada cultura e definidas por rituais.

Mas, quem são os jovens? Os jovens são entendidos, conforme critério da Organização Ibero-Americana de Juventude (2005), como as pessoas que têm entre 15 e 24 anos de idade. Porém esses limites etários não são fixos nem definem a juventude. Nas classes sociais mais favorecidas, a juventude é prolongada, o tempo de formação profissional aumenta e, devido a isso, as responsabilidades adultas são postergadas de forma legitimada, como aponta Abad (2003). Já nas classes populares brasileiras, a juventude se tornou um período de estigmatização social. Cabe, também, registrar que

\footnotetext{
${ }^{1}$ Universidade Estadual da Paraíba, Brasil.

${ }^{2}$ Universidade Estadual da Paraíba, Brasil.
} 
há, na atualidade, um alongamento da adolescência, que leva jovens adultos a manterem um modo de funcionamento psíquico antes próprio dos mais novos. (Savietto, 2012).

Assim, além da faixa etária, é preciso considerar que o conceito de juventude, como afirma Takeuti (2012), é apresentado de formas diferentes, de acordo com o contexto social, político, econômico e cultural de cada sociedade. Portanto, a concepção de juventude é constituída a partir de critérios históricos e culturais (Dayrell, 2003a).

A pluralidade de situações de vida dos jovens faz com que se defenda o emprego do termo juventudes no lugar de juventude. Sposito (2003: 60) apoia essa ideia, ao afirmar que "tem sido recorrente a importância de se tomar a ideia de juventude em seu plural - juventudes - em virtude da diversidade de situações existenciais que afetam os sujeitos.".

A compreensão de que cada momento do ciclo de vida - a infância, a juventude, a maturidade e a velhice - tem suas singularidades, demanda do Estado intervenções diversas, ou seja, políticas públicas especificamente destinadas a cada grupo (Sposito, 2003). A juventude representa um momento da existência humana, com características específicas e necessidades próprias (Abad, 2003). No entanto, durante um longo período, a juventude foi uma parte da população negligenciada pelas políticas públicas, incluída somente nas políticas destinadas à população como um todo.

As políticas públicas para a juventude são construídas a partir da ideia que se tem desse grupo e refletem as percepções dominantes sobre os jovens (Abad, 2003; Sposito, 2003). Acreditamos, então, que, para que a implantação das políticas públicas para a juventude seja eficiente e se desenvolva através de novas estratégias de ação, é fundamental pensar sobre a identidade dos jovens e a forma como veem a si mesmos. Para isso, é necessário que se realizem estudos sobre e com a juventude brasileira.

Motivadas por essa perspectiva, desenvolvemos uma pesquisa com jovens, estudantes do Ensino Médio da cidade de Campina Grande/PB, cujo objetivo foi o de analisar as identidades que constroem em seus relatos sobre o que é ser jovem e sobre os seus projetos de futuro. Neste artigo, fazemos um recorte desta pesquisa e organizamos a apresentação dos resultados em dois blocos. O primeiro refere-se ao que é ser jovem para os entrevistados e os sentimentos associados a isso; e o segundo, às perspectivas de futuro que se constroem nesses relatos e a participação do governo na concretização desses planos. 


\section{Método}

Optamos por uma metodologia qualitativa de pesquisa, cujo universo foi composto de estudantes do terceiro ano do Ensino Médio, das duas maiores escolas públicas da cidade de Campina Grande/PB - a Escola Estadual de Ensino Fundamental e Médio Dr. Hortêncio de Sousa Ribeiro, também conhecida como PREMEN, e a Escola Estadual de Ensino Médio Dr. Elpídio de Almeida, mais conhecida como Colégio Estadual da Prata, fundado em 31 de janeiro de 1953, pelo então governador do estado da Paraíba, José Américo de Almeida. Oferece Ensino Médio e Ensino Técnico Integrado. Atualmente tem cerca de 1300 alunos. Já o PREMEN foi fundado em 1980, como parte do Programa de Extensão e Melhoria do Ensino (PREMEN), numa parceria entre o Ministério da Educação (MEC), o Banco Internacional de Reconstrução - BIRD - e o Governo do estado da Paraíba. Atualmente, a escola tem, aproximadamente, 620 alunos e oferece Ensino Médio e Ensino Técnico Integrado. ${ }^{3}$ Por serem as maiores, essas escolas reúnem alunos de diferentes origens e contextos sociais.

Os jovens foram entrevistados no espaço escolar, com autorização da direção das escolas e de acordo com o critério de acessibilidade. Depois que assinaram o Termo de Consentimento Livre e Esclarecido (TCLE), realizamos as entrevistas, que foram gravadas em gravador digital, seguindo um roteiro semiestruturado. Esse tipo de entrevista, por ser um processo interativo e flexível, valoriza a fala dos entrevistados e permite que se expressem livremente, a partir do foco principal colocado pelo investigador. (Nogueira-Martins; Bógus, 2004).

Entrevistamos 15 estudantes, 11 dos quais tinham 18 anos de idade, e quatro, 19. Quanto ao sexo, dez eram do sexo feminino, e cinco, do masculino. Desses, nove eram alunos do Colégio Estadual da Prata, e seis, do PREMEN. Todos se declararam solteiros. A maior parte começou a estudar aos três ou quatro anos de idade, e poucos, aos cinco, seis ou sete anos. Todos nasceram na cidade de Campina Grande, exceto uma entrevistada, que nasceu no Rio de Janeiro. Os entrevistados residiam em dez diferentes bairros da cidade de Campina Grande, a saber: Prata, Palmeira, Bairro Universitário; Araxá, José Pinheiro, Ligeiro, Santa Rosa, Bela Vista, Catolé e Vila Cabral. Alguns deles, nas cidades vizinhas de Queimadas e Lagoa Seca.

\footnotetext{
${ }^{3}$ Informações disponíveis em: <http://www.colegiodaprata.xpg.com.br/>; <http://premencg. xpg.uol. com. br/>. Acessado em: 04/07/17.
} 
A análise das entrevistas foi feita empregando-se o método de análise de conteúdo proposto por Minayo (2004), denominado de método hermenêutico-dialético e que tem dois pressupostos básicos: o primeiro é o de que não há ponto final nem consenso na produção do conhecimento, e o segundo, de que a ciência se constrói na dinâmica entre experiência e razão. A fala do sujeito entrevistado é contextualizada. A abordagem dialética atua em nível dos significados e das estruturas, estas últimas entendidas como ações humanas objetivadas, logo, portadoras de significado.

A análise proposta pela referida autora divide-se em três fases principais. A primeira é a de ordenação dos dados. Nessa fase, faz-se um mapeamento dos resultados obtidos, num processo que envolve aspectos como a transcrição de entrevistas, a releitura e a organização dos relatos. A segunda é a da classificação dos dados, em que é feita, depois de uma leitura exaustiva das entrevistas, a categorização dos resultados a partir do que é considerado relevante nas entrevistas. Na terceira fase, a análise final, é feita a articulação entre a fundamentação teórica e os dados obtidos em campo, para responder às questões da pesquisa com base nos objetivos.

Vale salientar que todos os nomes dos entrevistados que são citados no decorrer deste artigo são fictícios.

\section{Sobre o que é ser jovem}

Quando solicitados a falar sobre o que significava 'ser jovem', grande parte dos entrevistados disse que essa era uma fase de preparação para o futuro:

ENTREVISTADORA: Para você, o que é ser jovem?

André: Ser jovem pra mim?... Assim, é uma... das fases que constrói o caráter da pessoa. É o que... vai refletir o futuro da gente, se a gente é... um... jovem tipo... que busca conhecimento, aprendizagem, é o reflexo que a gente vai ter no futuro, se a gente é uma pessoa desinteressada... o reflexo... no futuro... vai ser de uma vida malsucedida. (18 anos, Escola Estadual da Prata).

ENTREVISTADORA: Para você, o que é ser jovem?

Fernanda: Ser jovem é ter o direito de fazer suas escolhas pra o futuro. E ter a certeza que você tá fazendo a escolha certa pra não prejudicar depois... o futuro.

ENTREVISTADORA: Não se prejudicar depois?

Fernanda: É.

ENTREVISTADORA: E como seriam essas escolhas?

Fernanda: Tipo... fazer no caminho certo, ter suas responsabilidades, procurar fazer as coisas certas, e as escolhas profissionais também. (18 anos, Escola Estadual da Prata). 
A palavra futuro aparece três vezes no trecho do relato de André e, duas vezes, no de Fernanda. Isso nos remete à ênfase que os entrevistados dão à ideia de que a juventude é um período decisivo para se definir todo o futuro da pessoa, devido às importantes decisões que devem ser tomadas nessa fase e às consequências decorrentes delas na fase adulta. Os relatos, de modo determinista, defendem que, se não forem feitas as escolhas "certas", o futuro será "prejudicado": "o reflexo... no futuro... vai ser de uma vida malsucedida." (André).

É importante salientar que não desconsideramos que essa ênfase no futuro pode ter sido influenciada pelo fato de termos informado que o objetivo da pesquisa era de saber, também, quais eram os projetos de futuro deles. Porém, não podemos desconsiderar, como aponta Dayrell (2003a), que a visão de que os jovens estão se preparando para o futuro é muito comum, tanto entre os próprios jovens quanto em outros grupos etários. A juventude é, por vezes, vista como um 'vir a ser', uma condição transitória, o que é problemático, pois levaria a uma negação da vivência do presente. Como afirmam Castro, Abramovay e De Leon (2007), o jovem é o amanhã, mas também é o hoje, numa relação dialética. A juventude deve, então, ser pensada como presente e futuro e não, apenas, como uma ou outra condição.

A diversão também foi apontada por outros entrevistados quando perguntados sobre o que é ser jovem:

Adelaide: Ser jovem é saber viver, curtir a vida. (19 anos, Escola Estadual da Prata).

Tainá: Jovem é ir pra festa, aproveitar muito, ter amigo, sair... diversão. (19 anos, Escola Estadual da Prata).

Ainda em relação a esse aspecto, os entrevistados ressaltaram que esse 'saber viver' significa agir segundo a própria vontade, sem se importar com a opinião dos outros:

ENTREVISTADORA: Para você, o que é ser jovem?

Aline: Ser jovem é saber viver, porque as pessoas dizem que a pessoa ser jovem não pode fazer tudo, tudo o que... dá na telha, por ser muito jovem assim e tal... mas se a pessoa deixar de fazer o que ela quer, no futuro ela vai querer fazer e não poder fazer mais. Muitas vezes os pais não deixa sair quando é jovem, ai... quer sair quando tá casado, e o marido não deixa. Ai sempre tem essa... esse porém.

ENTREVISTADORA: Como seria saber viver?

Aline: Saber aproveitar a vida. Não... não... pensar, entre aspas, que o povo fala, mas se eu for pensar em tudo que for falar, a pessoa não vive, não faz nada que dê vontade, vai deixar de fazer as coisas por causa dos outros. (18 anos, PREMEN). 
Diferentemente de André e de Fernanda, cujas falas foram explicitadas anteriormente, o relato de Aline, embora remeta também ao futuro, exalta a necessidade de se "fazer tudo o que se quer" no presente. "Ser jovem é saber viver", é "aproveitar a vida" se guiando pela própria vontade, pois, "no futuro, ela vai querer fazer e não poder fazer mais". Se, para André e Fernanda, o foco é no futuro, porque é um reflexo do presente, para Aline, o foco é no presente, já que, no futuro, não se poderá fazer tudo o que se quer. Apesar de diferentes, esses discursos constroem posturas fatalistas típicas da ideologia neoliberal. (Gadotti, 1997).

Blanco e Diáz (apud Ximenes e Cidade, 2016) alertam que o fatalismo é um fenômeno social que está presente na atualidade não só entre os pobres. É preciso considerar que viver em contextos muito individualistas, onde a incerteza, a insegurança e a indefinição diante do futuro imperam, contribui para fortalecer o fatalismo em nossa sociedade.

O relato de Aline, ao defender a necessidade de viver o presente, e a ideia de que só é possível 'curtir a vida' na juventude, valoriza ainda a juventude em detrimento das demais fases da vida, como se só fosse possível se divertir enquanto se é jovem. A ideia de que 'ser jovem é aproveitar a vida' também foi ponto amplamente citado em estudo realizado por Gonçalves e Knauth (2006) com jovens que engravidaram ainda adolescentes e suas mães. 'Aproveitar a vida' seria, tanto para as mães quanto para as filhas, sair, passear, namorar, dançar e curtir, portanto, a juventude seria a época de desfrutar a vitalidade dos anos.

Dayrell (2003a) ressalta que, na atualidade, existe uma visão de que a juventude é um tempo de prazer, de liberdade, de comportamentos exóticos. Segundo o autor, tal visão resultaria, dentre outros fatores, da influência da indústria cultural e do mercado de consumo voltado para os jovens.

Na modernidade, impõe-se ainda a necessidade de se viver o presente, o 'agora', não perder as oportunidades, e isso é causado por uma constante incerteza sobre o futuro. (Bauman, 1998). Moreira, Rosário e Santos (2011) reforçam essa ideia afirmando que existe, atualmente, uma necessidade de se satisfazer no presente e de usufruir os prazeres da vida na juventude, como se não houvesse futuro. A ideia é de que, se tudo é relativo e provisório, só nos resta viver intensamente o agora. Há, também, uma visão da juventude como tempo de liberdade, principalmente para os 
homens. (Mauger, 2013). É necessário "aproveitar a juventude” antes que esse "tempo de liberdade" termine com a chegada das responsabilidades adultas.

A ideia de que, na juventude, deve-se fazer tudo o que se quer, guiar-se pela própria vontade, valoriza a satisfação dos próprios desejos individuais, independentemente dos desejos dos demais. Como alertam Moreira, Rosário e Santos (2011), a priorização do eu, dos prazeres pessoais é uma das marcas da juventude atual. O individualismo é um dos fatores que participam da construção das identidades na contemporaneidade (Silva, 2009), em que há uma focalização nos desejos individuais e particulares e um consequente distanciamento das necessidades coletivas (Ximenes; Cidade, 2016).

'Ser jovem' também foi apontado pelos entrevistados como um estado de espírito, uma maneira de agir. Segundo Artur, abaixo, qualquer um pode ser jovem se agir como tal:

Ser jovem é a pessoa... sempre ter aquele espírito de juventude independente da idade... não é ser jovem como é por ai... ir pra festa, beber, farrar. Ser jovem é sempre ser espontâneo, independente dos problemas, independente da idade sempre manter aquele espírito de jovem mesmo. [...] eu acho que jovem não se carrega... não se qualifica como uma categoria... criança, adulto, jovem, não... jovem... quem quiser ser jovem é pra sempre ser... quem quiser... o importante não é a idade, é como a pessoa se sente... isso é que é ser jovem. (18 anos, Escola Estadual da Prata).

No discurso de Artur, também impera a vontade própria, o "querer": “quem quiser ser jovem é prá sempre ser... quem quiser...". No entanto, diferentemente de alguns entrevistados, ele afirma que ser jovem não é "ir prá festa, beber, farrar”, é ser “espontâneo", manter "espírito de jovem”. Nessa perspectiva, a juventude é algo que transcende as características físicas: "o importante não é a idade, é como a pessoa se sente... isso é que é ser jovem".

A juventude não seria um período cronológico nem ir a festas, mas uma forma de agir que qualquer pessoa, em qualquer idade, poderia desenvolver. Isso é o que Dourado e Leibing (2002) chamam de 'descronologização da vida'. Segundo as autoras, na contemporaneidade, a juventude deixou de ser considerada como um grupo etário e tornou-se um bem, que pode ser adquirido através de formas de consumo adequadas e estilos de vida. Assim, os mais velhos fazem de tudo para parecer mais novos, o "que podemos chamar de 'juvenilização da cultura'." (Abad, 2003: 27, grifo do autor). Quanto a isso, Savietto e Cardoso (2012) ressaltam que a adolescência se tornou o ideal 
cultural contemporâneo. Como estilo de vida livre, móvel e experimentador, ela é algo extremamente desejado e disponível nas prateleiras da atualidade.

Existe um convite a ser eternamente jovem, o que consistiria em viver intensamente a autonomia da idade adulta sem atender às responsabilidades dela. Gozar os prazeres da liberdade de não ser mais criança, sem assumir os deveres de adulto. "Por que se tornar adulto quando os adultos têm como ideal ser jovens?" (Moreira; Rosário; Santos, 2011: 462).

O "sujeito pós-moderno" é detentor de múltiplas identidades (Hall, 2006), que estão constantemente se empurrando, transformando-se e se deslocando. Logo, na contemporaneidade, repleta de oportunidades fugazes e de seguranças frágeis, não há espaço para identidades fixas, inegociáveis, imutáveis. É possível ter a identidade que se deseja e ser jovem em qualquer idade. "Se tudo é relativo e provisório, devo viver intensamente o meu agora, sem preocupar-me com o outro e o futuro, ser eternamente jovem". (Moreira; Rosário; Santos, 2011: 461).

\section{Sobre como os entrevistados se sentem sendo jovens}

Em relação à pergunta sobre como se sentem sendo jovens, parte dos entrevistados afirmou que se sente com responsabilidades. Alguns afirmaram gostar disso, e outros, não.

ENTREVISTADORA: Como você se sente sendo jovem?

Fernanda: Tem sempre responsabilidade, eu não gosto muito não...

ENTREVISTADORA: Não gosta?

Fernanda: Prefiro ser criança (risos)

ENTREVISTADORA: Prefere ser criança?

Fernanda: É muitas responsabilidades, você tem que fazer muitas escolhas.

ENTREVISTADORA: Muita responsabilidade?

Fernanda: É... (18 anos, Escola Estadual da Prata).

André: [...] Sendo que eu tenho uma responsabilidade muito grande, porque um dia o... futuro... de... pessoas, que serão da minha família, está nas minhas mãos (pausa) e até mesmo da sociedade que eu faço parte. (18 anos, Escola Estadual da Prata).

Assim como em estudo realizado por Brandão (2009), a questão da responsabilidade foi citada pelos jovens entrevistados, como se observou acima. Para Fernanda, é necessário ter responsabilidade em relação às escolhas. Como jovens, eles estariam assumindo a possibilidade de decidir questões importantes sobre seu futuro e o futuro dos outros, como ressalta André. 
Cabe ressaltar, ainda, que o último ano do Ensino Médio é um dos períodos mais críticos, porque o estudante precisa escolher o curso em que quer ingressar na universidade, estudar para o Exame Nacional do Ensino Médio (ENEM) e para concluir o Ensino Médio. Os estudantes são influenciados por esse sentimento de responsabilidade e pelo receio que parece surgir daí. Alguns se preparam para entrar no mercado de trabalho e, de modo geral, sofrem muita pressão dos familiares e de toda a sociedade. Há uma cobrança por escolhas corretas, para se preparar para o futuro. Diante de todas essas inseguranças, os jovens sentem a necessidade de agir da forma que consideram responsável.

A relação estabelecida pelos jovens entre juventude e responsabilidade demonstra seu receio diante das inseguranças sociais típicas da sociedade moderna. (Brandão, 2009). Segundo Leão, Dayrell e Reis (2011), os jovens acreditam que a capacidade de elaborar um plano para o futuro e de persistir nele se constrói como responsabilidade pessoal que vai explicar e justificar o lugar social depois de adulto, e isso é sobremaneira relevante para eles.

Já Priscila afirma que se sente bem devido ao fato de ter mais saúde do que seus pais:

ENTREVISTADORA: Como você se sente sendo jovem?

Priscila: Eu me sinto bem. [...] Eu me sinto com mais saúde do que os meus pais, porque os meus pais têm problemas de saúde, me sinto uma pessoa com saúde... (pausa) sei lá... (risos) num sei. (18 anos, PREMEN).

No relato de Priscila, a juventude aparece associada à saúde. A ideia de que a velhice está associada à doença é comum em nossa sociedade. Todos se sentem impelidos a buscar e permanecer jovens, pois a perda da juventude corresponderia a uma degradação do corpo, da sexualidade e da inteligência. (Takeuti, 2012). Essa busca pela juventude eterna é uma das marcas da sociedade contemporânea, como já ressaltado.

Ser jovem também foi associado a se sentir 'muito feliz', como se pode constatar no discurso abaixo: 
ENTREVISTADORA: Como você se sente sendo um jovem?

Marcos: Muito feliz.

ENTREVISTADORA: Feliz?

Marcos: (Silêncio) É... tô na flor da idade, né? Ser jovem é tudo. Nunca queria deixar de ser jovem. [...] Num sei explicar bem, mas... (pausa) namoro é... (pausa) festas, mas tirando tudo isso, né? eu queria... (pausa) num sei explicar, mas... no meu caso, né?, eu sendo jovem, eu tô muito atrás de fazer cursos, eu não sou muito de festas, sou mais de namorar e... de estudar, estudo muito. Aí eu já tenho alguns cursos, mas não estou preparado... ainda falta muito. (18 anos, PREMEN).

Marcos hesita em dizer o que o faz muito feliz. O silêncio e as pausas denunciam essa hesitação: “(Silêncio) É... tô na flor da idade, né? Ser jovem é tudo. Nunca queria deixar de ser jovem. [...] Num sei explicar bem, mas... (pausa) namoro é... (pausa) festas, mas tirando tudo isso, né?” e direciona o seu relato para os estudos: "sendo jovem, eu tô muito atrás de fazer cursos, eu não sou muito de festas, sou mais de namorar e... de estudar, estudo muito." Ele também exalta a juventude ao dizer que a felicidade que sente está associada ao fato de estar na "flor da idade": "ser jovem é tudo".

\section{Sobre os planos para o futuro}

Todos os entrevistados afirmaram que costumavam pensar no futuro, e na opinião de alguns, isso é essencial para o jovem, já que ele não sabe o que está por vir, por isso precisa se preparar. Alguns deixaram clara a preocupação com o futuro desconhecido, certo receio do que está por vir. Dentre os planos para o futuro, mencionaram passar no vestibular, formar-se e construir uma carreira:

ENTREVISTADORA: Você tem planos para o futuro?

Tainá: Terminar esse ano, se passar no vestibular, fazer a universidade de odontologia, se não passar, fazer curso, fazer concurso, trabalhar... (18 anos, Escola Estadual da Prata).

ENTREVISTADORA: Você tem planos para o futuro?

Marcos: Tenho. Já... nesse vestibular eu quero passar, porque eu tô estudando, eu pretendo ser um engenheiro. (18 anos, PREMEN).

ENTREVISTADORA: Você tem planos para o futuro?

Estela: Ah, eu queria me formar.

ENTREVISTADORA: Se formar?

Estela: (Silêncio) É... assim... (pausa) construir uma carreira, né? (pausa) e... dar... assim orgulho pros meus pais... essas coisas assim... só. (18 anos, Escola Estadual da Prata). 
Ainda sobre essa questão, outros entrevistados apontaram, além do estudo e do trabalho, o desejo de 'constituir uma família' como parte integrante dos seus planos para o futuro:

\begin{abstract}
André: Bem... eu quero fazer o curso superior de arquitetura (pausa) conquistar um emprego, quero também me casar (pausa) constituir uma família, ter filhos e num futuro mais breve eu pretendo além de concluir o ensino médio, começar a, a trabalhar... ter alguma coisa na qual possa me basear para construir meus... meus sonhos. (18 anos, Escola Estadual da Prata).
\end{abstract}

Nesses relatos, o trabalho, um elemento que contribui fortemente para a identidade do sujeito (Morin; Tonelli; Pliopas, 2007), e o desejo de construir uma carreira aparecem como alguns dos elementos principais nos planos de futuro, embora André também mencione o desejo de constituir uma família. Os estudos de Lachtim e Soares (2011) afirmam que o trabalho é visto de forma muito positiva pelos jovens de diferentes classes sociais. A inserção no mercado de trabalho é a principal preocupação dos jovens, porquanto é um mecanismo por meio do qual podem alcançar outros objetivos, como a formação da família e a independência financeira.

Conforme IBASE/Polis (2008), o trabalho é visto pelos jovens com idades entre 18 e 22 anos, principalmente como necessidade, fonte de independência e de realização pessoal. Comparado com as demais faixas etárias, a percepção do trabalho como necessidade é menor entre os jovens. Por outro lado, a visão de trabalho como realização pessoal é maior. Cabe registrar que em estudo realizado com jovens executivos brasileiros, Morin, Tonelli e Pliopas (2007) identificaram a satisfação pessoal como um dos principais sentidos associados ao trabalho.

Os autores citados ressaltam que a independência é, também, um dos principais aspectos associados ao trabalho. A independência adquirida com o trabalho é mais valorizada pelos que têm entre 18 e 22 anos de idade, por ser um elemento essencial na construção da autonomia em relação à família, tanto por causa da renda que passam a ter quanto pelo fato de serem mais respeitados quando se tornam trabalhadores. $\mathrm{O}$ dinheiro ganho com o trabalho é associado à perspectiva de autonomia e de independência. Essa autonomia tanto pode ser no presente quanto no futuro. A pessoa trabalha muito e acredita que conseguirá alcançar sonhos e objetivos profissionais e pessoais. 
Os estudantes afirmaram, ainda, que, quando estiverem com a idade dos pais, pretendem ter uma vida estável, estar realizados ou ter conquistado tudo.

ENTREVISTADORA: E como você se imagina quando estiver com a idade dos seus pais?

Luana: Mais jovens que eles, mais bem de vida, conquistado tudo que eu desejo. ENTREVISTADORA: Conquistado tudo?

Luana: É... ou, pelo menos, a metade.

ENTREVISTADORA: Pelo menos a metade?

Luana: Sim. (18 anos, Escola Estadual da Prata).

Marcos: Me imagino não estar trabalhando mais...estar estável... já ser aposentado e viajando por aí, eu e minha mulher. (18 anos, PREMEN).

No que diz respeito a essa questão, alguns entrevistados disseram que têm mais oportunidades do que seus pais tiveram e que pretendem aproveitar isso:

ENTREVISTADORA: E como você se imagina quando estiver com a idade dos seus pais?

Fernanda: (Silêncio) Eu quero tá bem de vida (pausa)... ter alguma coisa pra não ter que trabalhar tanto como temos que trabalhar hoje por não ter tido... como é que eu posso dizer (pausa) uma... uma... oportunidade quando mais novos, não ter tido tantas escolhas como nós jovens podemos ter hoje em dia. (18 anos, Escola Estadual da Prata).

Como salientam Oliveira et al (2001), a percepção da educação como fator importante para o futuro decorre da ligação do estudo à ascensão social. Os jovens só valorizam a educação através da escola formal e do 'conhecimento útil' para se qualificar profissionalmente. (Lachtim; Soares, 2011). À transmissão do conhecimento acumulado e à formação ampla não seria dada a devida importância. O estudo é, pois, apenas um passo para se conseguir o emprego desejado:

ENTREVISTADORA: Você tem planos para o futuro?

Rebeca: Tenho, tenho muitos planos para o futuro (pausa)... como eu quero, pretendo entrar na PRF [Polícia Rodoviária Federal], só que tem que ter ensino superior [...] num tava pensando de fazer faculdade, tava pensando de fazer só a prova e entrar. Não é fácil, quando eu soube, eu disse é agora que eu tenho que correr atrás do prejuízo porque eu num tava estudando quase nada pro vestibular... agora eu tô estudando, agora só quem sabe é Deus se eu vou passar ou não, agora se eu num conseguir passar esse ano, ano que vem eu tento novamente, né? (19 anos, PREMEN). 
Vale ressaltar que os cursos universitários citados pelos entrevistados foram: Medicina, Odontologia, Arquitetura, Letras, Arte e Mídia, Engenharia, História e Educação Física. O Curso de Odontologia foi citado duas vezes, e Arte e Mídia e História foram citados como segunda opção. Na cidade de Campina Grande, existem duas universidades públicas: a Universidade Estadual da Paraíba (UEPB) e a Universidade Federal de Campina Grande (UFCG), que dispõem de diversos cursos em diferentes áreas do conhecimento; o Instituto Federal de Educação, Ciência e Tecnologia da Paraíba (IFPB), que oferece cursos de nível médio, técnico e superior, além de cinco faculdades particulares. Ingressar nas universidades locais, públicas ou privadas faz parte dos planos dos jovens, como podemos constatar nestas falas:

ENTREVISTADORA: O que é importante para realizar esses planos?

Rebeca: Eu?... Pra realizar o meu sonho? (pausa) terminar agora, né?, o ensino médio, conseguir, principalmente, entrar na universidade [...] terminar o meu curso daqui a uns quatro anos pra poder entrar... porque eu quero fazer educação fis... como é que se diz?... [...] Porque eu entrei na UEPB. Entrei não, como é que se diz?...Fiz vestibular pra... educação física, mas eu não quero ser professora, eu quero, como eu já disse, entrar pra PRF, só que tem que ter o ensino superior... é isso, né? (19 anos, PREMEN).

ENTREVISTADORA: Você tem planos para o futuro?

Guilherme: Tenho, é... eu pretendo... cursar a faculdade de... da carreira militar, mas não nesse ano, que nesse ano deu algumas coisas erradas, mas é, posteriormente eu pretendo sim seguir a carreira militar. Mas, no momento, se eu passar no vestibular esse ano, se eu num passar, conseguir um emprego formal pra tentar pagar alguma faculdade particular e se não eu vou fazer, tentar novamente na federal ou na estadual pra ver se eu passo em algum curso bom. Ou então, se não passar em nenhum curso bom, vou tentar... continuar tentando a carreira militar. Mas, no momento, eu pretendo fazer odontologia e arte e mídia na UFCG. (19 anos, PREMEN).

Quanto à importância de constituir uma família, Gonçalves (2005: 219), com base em semelhante pesquisa, constatou que isso parece indicar que, no Século XXI, no Brasil, a família permanece como polo de aglutinação social e ainda é uma forte referência das subjetividades, juntamente com a rede que se estrutura em torno dela. Apesar das pressões da modernidade contrárias a isso, a tradição cultural dos laços de parentesco permanece, "pondo em questão a extensão em que a noção de individualismo pode ser aplicada à juventude brasileira.”. 
Já Borges, Magalhães e Féres-Carneiro (2014) ressaltam que os projetos de família, atualmente, têm novos contornos. Devido ao grande individualismo da nossa sociedade, a liberdade e a fluidez nas relações se tornaram elementos essenciais nas novas ideias de família. Embora o casamento ainda seja considerado modelo ideal por alguns, houve um fortalecimento da ideia de que ele restringe as liberdades individuais, o que é algo indesejado pela maioria. Assim, o centro da família passa a ser os filhos, o que contribui para que os indivíduos se sintam mais livres e para que as relações sejam mais fluidas.

Outro fator que podemos perceber nas falas é o anseio por condições financeiras estáveis, que decorreriam de sucesso profissional e seriam necessárias para a realização do desejo de constituir família. Brandão (2009) também identificou uma preocupação com a autonomia e a estabilidade financeira entre os jovens, para os quais seria difícil lidar com as limitações financeiras de suas famílias, nesse caso, a preocupação financeira faria parte não só do futuro, mas também do presente. Essa condição poderia diminuir as expectativas de sucesso e estimular os jovens a se esforçarem mais rumo a uma formação profissional de acordo com as exigências da sociedade.

\section{Sobre a não concretização dos planos para o futuro}

Aos entrevistados também perguntamos: "Caso os seus planos não se realizem, você teria outros?" Alguns responderam que sim, e outros, que não têm outros planos. Os primeiros reafirmaram a necessidade de se preparar para o futuro. Alguns disseram que têm diferentes planos, mas a prioridade é alcançar o projeto pensado inicialmente. Outros afirmaram que é fundamental ter outros projetos, como Túlio, que afirma que devemos ter um plano $\mathrm{B}$, porquanto precisamos nos preparar para que o futuro não nos surpreenda, e os objetivos possam ser alcançados:

ENTREVISTADORA: Caso os seus planos não se realizem, você teria outros?

Túlio: Claro, claro que sim. Creio que a gente precisa muito ter um plano B em nossa mente, nossas mentes... [...] creio que você precisa ter o plano $\mathrm{B}$, caso não dê certo; creio que você precisa ter uma (pausa) tipo uma questão de planejamento, porque o que você precisa... a... ter... precisa ter tudo em mente, preparado, para que no futuro não... o futuro não lhe pregue surpresas, não lhe pregue peças. Então creio que se você tiver um segundo plano, tudo planejadinho e direitinho, creio que você consegue chegar onde você quer ir. (19 anos, Escola Estadual da Prata). 
Os planos alternativos são considerados pelos jovens como outras formas de conseguir exercer os papéis que planejaram inicialmente. Em suas falas, como se observa no relato de Túlio, eles demonstram, também, a necessidade de controlar o futuro. É preciso organizar tudo, planejar e controlar o amanhã: "tudo planejadinho e direitinho, creio que você consegue chegar onde você quer ir".

Dessa forma, esses outros planos surgem como alternativas possíveis diante das dificuldades de executar o que foi pensado. A juventude seria um período em que a pessoa poderia encontrar seu lugar no mundo. Ou seja, decidir o que deseja, ou não, fazer na vida, tomar decisões que influenciarão seu futuro (Mauger, 2013). Nessa fase, o jovem que se vê diante da impossibilidade de concretizar seus planos decide ajustar suas disposições às possibilidades acessíveis.

Outras respostas para esse questionamento se referiram ao casamento:

ENTREVISTADORA: Caso os seus planos não se realizem, você teria outros?

Tainá: Ah! Então, eu só vejo só mesmo casar... tá casada.

ENTREVISTADORA: Só casar?

Tainá: Sim... se num der tudo certo, hein?... se num ter estudo, num arrumar um emprego... a única opção é essa. (19 anos, Escola Estadual da Prata).

ENTREVISTADORA: Caso os seus planos não se realizem, você teria outros? Priscila: Outros planos? ... (pausa) Eu acho que se a mulher, ela não for... ela não tiver seu trabalho, não tiver seu estudo, ela vai depender do homem. E eu acho que isso é um costume muito errado assim... você pensar dessa forma, pelo fato de já ... já... da vida da mulher, desde antes até agora, eu acho que você deve pensar no que vai fazer... pensar em você... em você e no seu futuro... (pausa) e não ficar dependendo de marido, eu acho assim... (18 anos, PREMEN).

Esses relatos trazem questões vinculadas à identidade de gênero. Tainá coloca em último lugar a alternativa do casamento. Priscila parece excluir essa possibilidade ao defender que a mulher não deve 'depender de marido': “eu acho que você deve pensar no que vai fazer... pensar em você... em você e no seu futuro... (pausa) e não ficar dependendo de marido, eu acho assim...".

Os relatos nos aproximam das colocações feitas por Negreiros e Feres-Carneiro (2004), quando afirmam que, apesar das diferenças hierarquizadas entre os gêneros, as mulheres estão mais propensas a inovações e rupturas com as condições de desigualdade. 
Quanto aos estudantes que afirmaram não ter planos alternativos, relacionaram isso a 'ter o foco', no momento, apenas nos projetos atuais.

ENTREVISTADORA: Caso os seus planos não se realizem você teria outros? Aline: (Silêncio) No momento só penso no que eu quero agora, o que eu penso mais pra frente, mas, agora, pensar no que eu quero muito mais, num vou conseguir fazer o que eu quero agora, pra fazer o que eu quero mais pra frente ainda. (18 anos, PREMEN).

Ainda sobre esse aspecto, Antônia afirma que, só quando estiver diante da situação, é que pensará no que fazer, porque acha complicado pensar em planos alternativos, portanto considera importante continuar tentando alcançar os objetivos.

ENTREVISTADORA: Caso os seus planos não se realizem, você teria outros? Antônia: (Silêncio) Aí é complicado responder, né? Porque eu acho que também já entra numa parte que você num (pausa) é uma coisa na hora, um momento, né? que sonho todo mundo tem, ai na hora é outra coisa, né? (pausa) ai se não der certo, se puder tentar de novo a gente tenta e se não der a gente corre atrás de outras coisas, e no final, a gente (pausa) sempre consegue alguma coisa, eu acho, se a pessoa realmente quer, ela consegue. (18 anos, Escola Estadual da Prata).

O silêncio de Antônia, seguido de várias pausas, indica que ela hesitou ao responder a pergunta. Essa hesitação é resolvida através da máxima "querer é poder": "sempre consegue alguma coisa, eu acho, se a pessoa realmente quer, ela consegue." A ideia de que "querer é poder" e de que só a boa vontade resolve implica uma concepção ideológica de que tudo depende de cada um e que se ignoram as determinações sóciohistóricas (Minetto; Martins, 2001). Desconsidera-se que querer é necessário, mas não suficiente.

\section{Sobre o que é importante para realizar os planos}

Quando questionados sobre o que acreditavam ser necessário para concretizar seus planos, os estudantes fizeram referência, quase que exclusivamente, a fatores individuais, como se tudo dependesse apenas de nós mesmos. Dentre os fatores individuais citados como essenciais para a concretização dos seus planos, destacou-se 'ter determinação'. 
ENTREVISTADORA: E o que é importante para realizar esses planos?

Aline: O que é importante pra realizar esses planos?... é... ser determinada, saber o que quer e ir... ir à procura, porque se for esperar pelo povo, essa pessoa num faz nada. ENTREVISTADORA: Ir à procura?

Aline: É.

ENTREVISTADORA: Como seria essa procura?

Aline: Se você quer um trabalho você tem que ir à procura, ele não vem a você, você tem que ir atrás dele. Nada vem de mão beijada prá você. (18 anos, PREMEN).

Artur: Determinação, fé e não desistir jamais. Se você tiver força de vontade e tiver... meios viáveis pra prosseguir nisso então... nada lhe segura, vai em frente que você consegue. (18 anos, Escola Estadual da Prata).

A entrevistada Aline propõe a determinação e a busca dos objetivos como fatores centrais para concretizar planos. Artur também menciona a determinação como um fator essencial, mas se remete também à fé e à força de vontade.

'Saber fazer as coisas certas' também foi um fator apontado como importante para se concretizarem planos, além da 'responsabilidade'.

ENTREVISTADORA: E o que é importante para realizar esses planos?

Estela: Você tem... é... estudar, ter responsabilidade assim, no que tá fazendo. ENTREVISTADORA: Ter responsabilidade?

Estela: É, no que tá fazendo assim... é, não brincar, ser mais atenta, só.

ENTREVISTADORA: Como seria 'ser mais atenta'?

Estela: É... (pausa) é tipo assim... saber o que tá fazendo, pra você não poder assim errar. Eu sei que errar todo mundo erra, mas você planejando assim, tendo aquele controle assim... você sabe fazer as coisas certas.

ENTREVISTADORA: Como seria 'saber fazer as coisas certas'?

Estela: (Silêncio) Ah, depende, né?... de várias coisas assim... porque... você às vezes não faz, né? tudo certo, você tem que pensar bastante antes de fazer aquela coisa que você quer.

ENTREVISTADORA: Pensar bastante?

Estela: É. (18 anos, Escola Estadual da Prata).

Alguns entrevistados afirmaram, ainda, que, para realizar seus planos, é essencial entrar para a universidade.

Rebeca: Eu?... Pra realizar o meu sonho? (pausa) terminar agora, né? o ensino médio, conseguir principalmente entrar na universidade, o que eu pretendo, né? (18 anos, PREMEN).

Outros atribuíram ao apoio da família e dos amigos o sucesso de seus planos, o que não implicou considerar o coletivo, mas os grupos de referência mais próximos. 
Túlio: O que é importante?... comprometimento por minha parte, estudo, responsabilidade... é... apoio tanto dos amigos quanto da família, isso é indispensável, creio que se você... fizer tudo de uma forma correta, lógico que imprevistos sempre acontecem, mas se você fizer tudo de uma forma correta, objetiva... e com apoio dos amigos e da família tudo vai dar certo, seja lá qual for seu plano, seja lá qual for a carreira que você quer seguir. (19 anos, Escola Estadual da Prata).

A pesquisa que realizamos mostrou que fatores individuais, como a determinação, a força de vontade e a responsabilidade estão fortemente presentes na forma como os jovens pensam em seus planos para o futuro e nos meios 'corretos' para realizá-los.

Segundo Silva (2009), o individualismo e fatores como a autorresponsabilização, o imperativo à atividade, a flexibilidade, a disposição para aprender, a tendência à indefinição identitária e a noção de ageless ou ausência de idade são elementos essenciais para a construção das identidades na contemporaneidade. Valoriza-se o indivíduo como principal responsável pelo sucesso de seus projetos, especialmente os que vivem em metrópoles, estimulados a competir e a consumir. (Gonçalves, 2005). O coletivo tornou-se pouco relevante nesse processo, em que fatores individuais são privilegiados, pois, mesmo quando os entrevistados falam em outras pessoas, o discurso se restringe à família e aos amigos.

\section{Sobre a participação do governo na concretização dos planos para o futuro}

No que diz respeito à pergunta: "Você acredita que, de alguma forma, o governo poderia ajudar a realizar esses planos?", todos os entrevistados disseram que sim. Sobre as formas como poderia fazer isso, a maioria afirmou que é na educação que o governo tem que investir para promover a concretização desses sonhos.

Cátia: Ah! O governo, eu acho que poderia ajudar na forma da educação, né? Primeiramente na escola... aí... porque da escola é que se tira a base para... o... universitário, entendeu? Aí eu acho... eu penso assim que o governo tinha que ajudar mais na educação, as novas agora... é... na tecnologia [...] Eu acho assim que devia mais... favorecer aos alunos. (18 anos, PREMEN).

Ainda sobre o que os jovens acreditam que o governo deve fazer para ajudar a concretizar seus planos, outros entrevistados falaram que ele deveria 'dar mais oportunidades' para os jovens, relacionadas tanto à já supracitada educação quanto ao emprego. 
ENTREVISTADORA: Você acredita que, de alguma forma, o governo poderia ajudar a realizar esses planos?

Antônia: (Silêncio) É... na questão profissional eu acho que sim, se for investindo mais na educação, né? porque no Brasil hoje em dia esses investimentos são muito precários (pausa) se o governo investir mais (pausa) e dar mais oportunidade também no mercado de trabalho, que é muito difícil pro jovem que tá começando, né? é difícil. Mas eu acho que é... é... é importante também que o governo ajude. (18 anos, Escola Estadual da Prata).

Marcos, abaixo, também cita essa necessidade relativa ao mercado de trabalho e aponta a importância de se criarem novos projetos voltados para o primeiro emprego.

\footnotetext{
Marcos: Pode... criando novos projetos, criaram só um, que é o primeiro emprego, mas deveria ter mais. Tipo assim criar convênios escolas, como novas empresas pra colocar esse jovem nessa empresa pra pegar uma experiência, pra no futuro já ter experiência pra pegar um trabalho melhor na sua área. Também... (pausa) é isso, acho que isso resolveria o caso. (18 anos, PREMEN).
}

Como vimos, os jovens acreditam que o Estado precisa investir mais na educação e em mais oportunidades no mercado de trabalho. Isso nos leva a pensar nas ações que o governo vem desenvolvendo em relação às políticas públicas para a juventude. Sobre esse aspecto, Lopes et al. (2008) asseveram que, embora a educação seja um direito assegurado constitucionalmente, as políticas educacionais são insuficientes, descontínuas e afastadas da realidade social que desejam atingir. Dayrell (2003b: 185) ressalta que o problema não é o acesso à escola, mas a qualidade do ensino oferecido pela instituição. Ele acrescenta que "a estrutura escolar e os projetos políticopedagógicos ainda dominantes nas escolas não respondem aos desafios que estão postos para a educação da juventude contemporânea".

Os entrevistados entendem que o governo deve desenvolver políticas públicas voltadas para a capacitação profissional do jovem e sua inserção no mercado de trabalho, investir nas escolas e estimular seu ingresso na universidade. Seus discursos se aproximam do que pensa Leite (2003: 158), quando afirma que se devem desenvolver políticas voltadas para todos os trabalhadores, mas, especialmente, para os jovens, que proporcionem "oportunidades de adquirir e comprovar qualificação e experiência que possam servir como credencial para o acesso ao mercado de trabalho". 
Cumpre registrar, no entanto, que o governo só foi citado quando a entrevistadora perguntou sobre a participação dele na concretização dos planos dos entrevistados, o que nos leva a questionar sobre em que medida esses jovens consideram realmente relevante o papel do Estado na realização de seus projetos para o futuro e se, realmente, identificam-se como sujeitos de direitos.

Por fim, cabe ressaltar que, na área da Psicologia Social crítica, perspectiva com a qual trabalhamos, destacam-se os estudos sobre identidade desenvolvidos por Antônio Ciampa. (2007, 2009). Esse autor defende que as identidades são múltiplas e mutáveis, são fenômenos sócio-históricos. Maheirie (2002) nos auxilia nessa discussão quando enuncia que as identidades são construídas por oposições, conflitos e negociações e estão sendo sempre reinventadas, num processo que nunca tem fim. No entanto, embora a identidade seja uma totalidade contraditória, múltipla e mutável, é una, isto é, somos uma unidade na multiplicidade (Ciampa, 2009).

Nos relatos dos jovens entrevistados, há o que referido autor denomina de "presentificação da representação de si mesmo, que foi cristalizada em momentos anteriores”, isto é, as 'imagens de si mesmo', construídas nos relatos, não rompem com o instituído. Em geral, os entrevistados constroem discursos em que aspectos da ideologia neoliberal como o fatalismo, o individualismo, a autorresponsabilização e a exaltação da juventude são ressaltados.

\section{Considerações finais}

Com o objetivo de colaborar para a elaboração de políticas públicas destinadas aos jovens, neste artigo, propusemo-nos a analisar as identidades construídas por estudantes de ensino médio e seus projetos de futuro. O caminho que traçamos para atingir esse objetivo consistiu em analisar o que é ser jovem, sob o ponto de vista desses estudantes, e os sentimentos associados a isso, como também suas perspectivas de futuro e o que pensam sobre a participação do governo na concretização desses planos.

Os relatos dos entrevistados apontam para a ideia de juventude como um momento de preparação para o futuro. Ser jovem também foi associado a divertir-se, a aproveitar e 'curtir a vida' e a 'saber viver'. A juventude é valorizada como melhor fase da vida. Identificamos, ainda, a concepção da juventude como um estado de espírito, o que remete à ideia de 'juventude eterna'. 
Ao falar sobre como se sentem sendo jovens, muitos deles disseram 'bem', outros, que se sentem 'felizes'. Ser jovem é ‘tudo'. Esses sentimentos foram associados às atividades desenvolvidas nessa fase, e a se sentir, por exemplo, com mais saúde do que os mais velhos. Alguns também declararam que se sentem com uma grande responsabilidade, devido a escolhas e decisões que devem tomar e que terão consequências para toda a vida.

Quanto aos planos para o futuro, os estudantes pensam, principalmente, em concluir o ensino superior, ingressar em uma carreira profissional e constituir uma família. O anseio por sucesso financeiro e estabilidade é parte relevante desses projetos. No que diz respeito às formas de alcançar esses objetivos, mencionaram, sobretudo, os fatores individuais, entre os quais, destacam-se a 'determinação', 'a força de vontade', o 'saber fazer as coisas certas', a 'responsabilidade' e a 'fé'. Alguns disseram que é importante a participação da família e dos amigos para a realização desses planos, porém não consideraram a importância de projetos sociais coletivos.

No que diz respeito à participação do governo na realização dos planos de futuro dos entrevistados, todos os estudantes afirmaram que o Estado pode ajudar na concretização dos seus planos. Para eles, a educação e o mercado de trabalho são as duas principais áreas em que o governo deveria investir para colaborar com a realização dos seus projetos. No entanto, o governo só foi citado quando questionamos sobre seu papel.

A presença do individualismo na construção das identidades desses jovens evidencia uma das marcas da ideologia neoliberal. Registramos a necessidade de novos estudos, em que seja aprofundada a relação entre a juventude e a atuação do Estado, o que contribuirá para o desenvolvimento de políticas públicas para a juventude e para que os jovens se percebam efetivamente como sujeitos de direitos. 


\section{Referências}

ABAD, Miguel. Crítica política das políticas de juventude. In: FREITAS, Maria Virgínia de; PAPA, Fernanda de Carvalho (Orgs.). Políticas públicas: juventude em Pauta. São Paulo: Cortez Editora, 2003. p. 13-32.

BAUMAN, Zygmunt. O mal-estar da pós-modernidade. Rio de Janeiro: Jorge Zahar Ed, 1998. BORGES, Carolina de Campos; MAGALHÃES, Andrea Seixas; FÉRES-CARNEIRO, Terezinha. Liberdade e desejo de constituir família: percepções de jovens adultos. Arquivos Brasileiros de Psicologia, v. 66, n. 3, p. 89-103, 2014.

Disponível em: <http://pepsic.bvsalud.org/scielo.php?script=sci_arttext\&pid=S180952672014000300008\&lng=pt\&tlng=pt $>$. Acessado em: 27/03/2017.

BRANDÃO, Carla de Sant'Ana. Expectativas sociais e projetos para o futuro: um retrato da juventude paraibana. In: Congresso Brasileiro de Sociologia, 14, 2009, Rio de Janeiro. Anais do XIV Congresso Brasileiro de Sociologia. Sociologia: consensos e controvérsias, Rio de Janeiro: SBS, 28-31, 2009, p. 1-20.

CASTRO, Mary Garcia; ABRAMOVAY, Miriam; DE LEÓN, Alessandro. Políticas para quem e para o quê. In:

(Orgs.). Juventude: tempo presente ou tempo futuro? Dilemas em propostas de políticas de juventude. São Paulo: GIFE - Grupo de Institutos, Fundações e Empresas, 2007. p.20-34.

CIAMPA, Antonio da Costa. A estória de Severino e a história de Severina. 9. ed. São Paulo: Brasiliense, 2007.

Identidade. In: S. T. LANE; CODO, W. (Orgs.). Psicologia Social: o homem em movimento. 13 ed., São Paulo: Brasiliense, 2009. p. 58-74.

DAYRELL, Juarez. O jovem como sujeito social. Revista Brasileira de Educação, n.24, p. 40 52, 2003a.

. Escola e culturas juvenis. In: FREITAS, Maria Virgínia de; PAPA, Fernanda de Carvalho (Orgs.). Políticas públicas: juventude em pauta. São Paulo: Cortez Editora, 2003b. p. 173-202.

DEBERT, Guita Grin. A antropologia e o estudo dos grupos e das categorias de idade. In: LINS DE BARROS, Myriam Moraes (Org.). Velhice ou terceira idade: estudos antropológicos sobre identidade, memória e política. 4 ed., Rio de Janeiro: Editora FGV, 2006. p. 49-68.

DOURADO, Márcia; LEIBING, Annette. Velhice e suas representações: implicações para uma intervenção psicanalítica. Estudos e pesquisas em Psicologia, v. 2, n. 2, p. 1-8, 2002.

GADOTTI, Moacir. Lições de Freire. Rev. Fac. Educ., v. 23, n. 1-2, 1997. Disponível em $<$ http://www.scielo.br/scielo.php?script=sci_arttext\&pid=S0102-

25551997000100002\&lng=en\&nrm=iso>. Acessado em: 24/04/2017.

GONÇALVES, Hebe Signorini. Juventude brasileira: entre a tradição e a modernidade. Tempo Social, v. 17, n. 2, p. 207-219, 2005.

GONCALVES, Helen; KNAUTH, Daniela Riva. Aproveitar a vida, juventude e gravidez. Rev. Antropol., v. 49, n. 2, p. 625-643, 2006.

Disponível em: <http://www.scielo.br/scielo.php?script=sci_arttext\&pid=S003477012006000200004\&lng=en\&nrm=iso>. Acessado em: 24/04/2017.

HALL, Stuart. A identidade cultural na pós-modernidade. 11. ed., Rio de Janeiro: DP\&A, 2006. IBASE - Instituto Brasileiro de Análises Sociais e Econômicas; POLIS, Instituto de Pesquisa Juventudes Sulamericanas. IBASE/PÓLIS, 2008.

LACHTIM, Sheila Aparecida Ferreira; SOARES, Cássia Baldini. Valores atribuídos ao trabalho e expectativa de futuro: como os jovens se posicionam? Trabalho, Educação e Saúde, v. 9, n. 2, p. 2011. 2017-294, Disponível em: <http://www.scielo.br/scielo.php?script=sci_arttext\&pid=S198177462011000200007\&lng=pt\&tlng=pt.>. Acessado em: 16/12/2015.

LEÃO, Geraldo; DAYRELL, Juarez Tarcísio; REIS, Juliana Batista dos. Juventude, projetos de vida e ensino médio. Educ. Soc., v. 32, n. 117, p. 1067-1084, 2011. Disponível em: http://www.scielo.br/scielo.php?script=sci_arttext\&pid=S0101-73302011000400010

Acessado em: 03/03/17 
LEITE, Elenice Moreira. Juventude e trabalho: criando chances, construindo cidadania. In: FREITAS, Maria Virgínia de; PAPA, Fernanda de Carvalho. (Orgs.). Políticas públicas: juventude em pauta. São Paulo: Cortez Editora, 2003. p. 153 - 171.

LOPES, Roseli Esquerdo et al. Juventude pobre, violência e cidadania. Saúde e sociedade, v.17, n. 3, p. 63-76, 2008.

MAHEIRIE, Kátia. Constituição do sujeito, subjetividade e identidade. Interações, v.7, n.13, p. 31-44, 2002. Disponível em: http://pepsic.bvsalud.org/pdf/inter/v7n13/v7n13a03.pdf

Acessado em: 14/04/17

MAUGER, Gérard. Juventude: idades da vida e gerações. Dados, v. 56, n. 1, p. 169-183, 2013. Disponível em: http://www.scielo.br/scielo.php?pid=S001152582013000100007\&script=sci_abstract\&tlng=es

Acessado em:10/03/17

MOREIRA, Jacqueline de Oliveira; ROSÁRIO, Ângela Buciano do; SANTOS, Alessandro Pereira dos. Juventude e adolescência: considerações preliminares. Psico, v. 42, n. 4, p. 457464, $2011 . \quad$ Disponível em: http://revistaseletronicas.pucrs.br/ojs/index.php/revistapsico/article/view/8943

Acessado em:14/04/17

MORIN, Estelle; TONELLI, Maria José; PLIOPAS, Ana Luísa Vieira. O trabalho e seus sentidos. Psicologia \& Sociedade, v. 19, Edição Especial 1, p. 47-56, 2007.

MINAYO, Maria Cecília de Souza. Desafio do conhecimento: pesquisa qualitativa em saúde. 8 ed., São Paulo: Hucitec, 2004.

MINETTO, Gerceley Paccola; MARTINS, Lília Christina de Oliveira. Participação popular e ação profissional do assistente social: elementos imprescindíveis para a transformação social. Serviço Social \& Realidade, v. 10, n.2, p.33-46, 2001.

NEGREIROS, Teresa Creusa de Góes Monteiro; FERES-CARNEIRO, Terezinha. Masculino e feminino na família contemporânea. Estudos e pesquisas em Psicologia, v. 4, n. 1, p.34-47, 2004.

NOGUEIRA-MARTINS, Maria Cezira Fantini; BÓGUS, Cláudia Maria. Considerações sobre a metodologia qualitativa como recurso para o estudo das ações de humanização em saúde. Saúde e Sociedade, v.13, n.3, p.44-57, 2004.

OLIVEIRA, Denize Cristina de et al. Futuro e liberdade: o trabalho e a instituição escolar nas representações sociais de adolescentes. Revista Estudos de Psicologia, v. 6, n.2, p. 245-258, 2001.

ORGANIZAÇÃO IBERO-AMERICANA DE JUVENTUDE. Ata da Convenção Ibero Americana dos Direitos dos Jovens. Espanha, 2005. 14 p. Disponível em: http://www.unfpa.org.br/Arquivos/convencao.pdf

Acessado em: 04/07/17

SAVIETTO, Bianca Bergamo. Juventude e família na contemporaneidade: um desamparo sem fim. Gerais: Revista Interinstitucional de Psicologia, v. 5, n. 1, p. 23-35, 2012.

Disponível em: <http://pepsic.bvsalud.org/scielo.php?script=sci_arttext\&pid=S198382202012000100003\&lng=pt\&tlng=pt.> . Acessado em: 18/09/2015.

SAVIETTO, Bianca Bergamo; CARDOSO, Marta Rezende. Idealização e onipotência na juventude contemporânea: a drogadicção como ilustração. Fractal, Rev. Psicol, v. 24, n. 2, p. 353-366, 2012. Disponível em: http://www.scielo.br/scielo.php?script=sci_arttext\&pid=S198402922012000200010\&lng=en\&nrm=iso\&tlng=pt

Acessado em:03/03/17

SILVA, Luna Rodrigues Freitas. Autonomia, imperativo à atividade e "máscara da idade": prerrogativas do envelhecimento contemporâneo? Psicologia \& Sociedade, v. 21, n. 1, p.128 134, 2009.

SPOSITO, Marília. Trajetórias na constituição de políticas públicas de juventude no Brasil. In: FREITAS, Maria Virgínia de; PAPA, Fernanda de Carvalho (Orgs.). Políticas públicas: juventude em pauta. São Paulo: Cortez Editora, 2003. p.57-75. 
TAKEUTI, Norma Missae. Paradoxos societais e juventude contemporânea. Estudos de Psicologia, v. 17, n. 3, p. 427-434, 2012. Disponível em: http://www.scielo.br/pdf/epsic/v17n3/11.pdf

Acessado em: 10/03/17

XIMENES, Verônica Morais; CIDADE, Elívia Camurça. Pobreza: implicações psicossociais do fatalismo. Revista Interamericana de Psicologia/Interamerican Journal of Psychology (IJP), v. 50, n.1, p. 128-136, 2016. Disponível em: http://www.repositorio.ufc.br/bitstream/riufc/18376/1/2016_art_vmximenes.pdf

Acessado em: 17/03/17

ZANELLA, Andréa Vieira et al. Jovens, juventude e políticas públicas: produção acadêmica em periódicos científicos brasileiros (2002 a 2011). Estudos de Psicologia, v. 18, n. 2, p. 327-333, 2013. Disponível em: http://www.scielo.br/scielo.php?script=sci_arttext\&pid=S1413294X2013000200019

Acessado em: 10/03/17

Recebido em: 30/05/2017.

Aprovado em: 07/07/2017. 